\title{
PELATIHAN DAN PENDAMPINGAN PENULISAN ARTIKEL ILMIAH HASIL PENELITIAN BERMUATAN PENDIDIKAN KARAKTER BAGI GURU MI SE-K3MI KECAMATAN KEDUNGKANDANG 1 KOTA MALANG
}

\author{
Siti Sumarsilah ${ }^{1}$, Susandi ${ }^{2}$, Anita Kurnia Rachman ${ }^{3}$ \\ ${ }^{1)}$ IKIP Budi Utomo, Malang, Jawa Timur, Indonesia \\ ${ }^{2)}$ IKIP Budi Utomo, Malang, Jawa Timur, Indonesia \\ ${ }^{3)}$ IKIP Budi Utomo, Malang, Jawa Timur, Indonesia \\ 1 sumarsilah1957@gmail.com \\ ${ }^{2}$ Susandi.ikipbudiutomo@gmail.com \\ 3.Anita27rachman@gmail.com
}

Teachers have the obligation to write articles as a form of creativity and achievement. Writing articles better in accordance with the field of science they have. Referring to the problem of the difficulty of writing scientific articles in the Teacher Working Group in K3-MI in Kedungkandang District 1, namely the teacher has not been able to choose themes, frameworks, write paragraphs, and determine theories in writing articles. Solutions offered, namely the teacher writes articles according to interests. Before writing articles it's better to write an article framework. Paragraph compilation which is cohesion and coherence. Theory for strengthening ideas and ideas. The method used aims to produce skills in writing articles. This stage includes discussion of work plans, training activities include the provision of theoretical and practical material, with a composition of $30 \%$ theory and $70 \%$ practice. Article writing activities are carried out with guidance. Program evaluation and monitoring to provide solutions to problems. Skill improvement for participants is in accordance with experiential learning theory. The trainees who are increasingly active in the training activities, the more knowledge they have because the more information they get. The conclusion of this activity is that teachers are better off writing articles according to their interests. Before writing an article it would be better to write a framework. Good writing is generated from the preparation of paragraphs that are cohesion and coherence. Theory is needed to strengthen ideas and ideas in writing.

keywords: training, mentoring, writing, scientific articles

\section{PENDAHULUAN}

Kecamatan Kedungkandang, Kota Malang terletak antara 112036'14"112040 '42" BT dan 077036'38'008001'57'LS. Kecamatan Kedungkandang terletak pada ketinggian 440-460 m diatas permukaan laut (dpl). Luas wilayah Kecamatan Kedungkandang, 3.989 $\mathrm{Ha}$ atau 39,89 km2 dengan batas wilayah sebagai berikut, sebelah Utara berbatasan dengan Kecamatan Pakis Kabupaten Malang, sebelah timur berbatasan dengan Kecamatan Tumpang dan Kecamatan Tajinan Kabupaten Malang, sebelah selatan berbatasan dengan Kecamatan Tajinan dan Kecamatan Pakisaji Kabupaten Malang, dan sebelah barat berbatasan dengan Kecamatan Sukun, Kecamatan Klojen dan Kecamatan Blimbing Kota Malang Jumlah Penduduk di wilayah Kecamatan Kedungkandang (Januari Siti Sumarsilah : Pelatihan Dan Pendampingan Penulisan Artikel I lmiah Hasil Penelitian Bermuatan Pendidikan Karakter Bagi Guru Mi Se-K3mi Kecamatan Kedungkandang 1 Kota Malang 
2018), yaitu $\mathbf{1 9 2 . 6 2 5}$ jiwa, terbagi menurut jenis kelamin, yaitu lakilaki 96.436 jiwa dan jumlah perempuan, yaitu 96.189 jiwa. Dengan luas wilayah Kecamatan Kedungkandang 39,89 Km2, kepadatan penduduk Kecamatan Kedungkandang , 76.742 .

Wilayah Kecamatan pada Tahun 2007 sudah dibangun sebuah sekolah TK dan SDN Nasional. Sekolah tersebut berada di wilayah Kelurahan Tlogowaru, Sedangkan sejak tahun 2009 di wilayah kelurahan Bumiayu sudah didirikan Universitas Terbuka Malang dan Universitas Negeri Malang Program PGSD ada di Kelurahan Madyopuro. Sehingga diwilayah Kecamatan Kedungkandang terdapat 2 Perguruan Tinggi Negeri dan 4 perguruan tinggi swasta. Fasilitas daerah dibidang kesehatan yang ada di wilayah Kecamatan Kedungkandang antara lain: RSUD Kota Malang (Kelurahan Bumiayu), Puskesmas Kedungkandang yang berada di Kelurahan Kedungkandang, Puskesmas Gribig di Kelurahan Madyopuro, Puskesmas Arjowinangun di Kelurahan Arjowinangun, Puskesmas Pembantu, Rumah Sakit Panti Nirmala di Kelurahan Kotalama, RSIA Refa Husada (Kelurahan Tlogowaru), dan beberapa klinik, praktek dokter lainnya. Fasilitas daerah dibidang kesehatan yang ada di wilayah Kecamatan Kedungkandang antara lain: Gelanggang Olah Raga (GOR) Ken Arok di Kelurahan Buring, Velodrome di Kelurahan Madyopuro, dan fasilitas olah raga lainnya seperti lapangan sepak bola, lapangan voli, lapangan badminton, dan lainnya.

Mengacu pada analisis situasi dan hasil diskusi bersama mitra mengenai kendala dan permasalahan mitra tentang kesulitan menulis artikel ilmiah di Kelompok Kerja Guru
Madrasah Ibtidaiyah yang tergabung dalam K3-MI di Kecamatan Kedungkandang 1, maka permasalahan yang yang ditemukan, yaitu 1) Guru belum mampu memilih tema tulisan artikel, 2) Guru belum mampu menyusun kerangka tulisan untuk menulis artikel, 3) Guru mengalami kesulitan ketika menulis paragraf dalam artikel, dan 4) Guru mengalami kesulitan menentukan teori yang sesuai dengan permasalahan yang dibahas.

Solusi yang ditawarkan untuk permasalahan yang ada, yaitu Guru lebih baik menulis artikel sesuai dengan minat yang disenangi. Menulis sesuai dengan bidang yang dikuasai. Hal ini bertujuan untuk menghasilkan tulisan yang baik dan berkualitas. Menyusun artikel bukan kegiatan yang tiba-tiba langsung jadi. Menulis artikel memerlukan waktu baik untuk artikel penelitian ataupun artikel konseptual. Sebelum menulis artikel akan lebih baik jika menulis kerangka terlebih dahulu agar hasilnya sistematis. Kerangka yang dibuat merupakan bagian-bagian dari artikel yang akan disusun. Menulis merupakan kegiatan yang memerlukan latihan berkali-kali. Tulisan yang baik dihasilkan dari penyusunan paragraf yang kohesi dan koherensi sesuai dengan tema yang dipilih. Teori diperlukan untuk penguatan ide dan gagasan dalam menulis. Pemilihan teori pun harus disesuaikan dengan teori yang relevan dan tidak lebih dari lima tahun. Hal ini karena teori yang baru dirasa akan lebih relevan dengan permaslahan yang muncul di lapangan.

\section{METODE PELAKSANAAN}

Pelaksanaan program pengabdian masyarakat Pendidikan bagi Masyarakat dilaksanakan di lokasi mitra, yakni MI Nurul Hikmah Kecamatan Kedungkandang 1 Kota 
Malang. Metode yang digunakan berupa pelatihan yang bertujuan untuk menghasilkan keterampilan dalam menulis artikel. Tahapan yang dilakukan terlebih dahulu dengan melakukan kegiatan ijin kepada ketua K3MI Kecamatan Kedungkandang 1 Kota Malang, yaitu Bapak Muhammad Shodik, S. Ag guna mengetahui permasalahan dan perencanaan pemecahan permasalahan yang dihadapi.

Tahapan pelaksanaan program Pendidikan bagi Masyarakat ini sebagai berikut. 1) Diskusi rencana kerja, pada tahapan ini dilakukan perencanaan secara menyeluruh dan rinci tentang agenda kegiatan yang akan dilaksanakan selama dua hari, yaitu tanggal 26-27 April 2019. 2) Pelatihan kegiatan meliputi pemberian materi teori dan praktek, dengan komposisi $30 \%$ teori; $70 \%$ praktek yang meliputi materi pemahaman tentang karya tulis ilmiah, penyusunan kerangka artikel, penulisan dan penyusunan paragraf yang baik. Pemberian teori dilaksanakan pada tanggal 26 April 2019

3) Kegiatan parktek menulis artikel dilaksanakan pada hari kedua, yaitu tanggal 27 April 2019. Kegiatan ini dilakukan dengan pimbingan dari pemateri untuk menghasilkan artikel sesuai dengan bidang yang dikuasai guru. 4) Evaluasi dan Monitoring program secara keseluruhan untuk memberikan solusi terhadap permasalahan yang timbul selama kegiatan dan kesiapan para guru setelah kegiatan Pengabdian Masyarakat program Pendidikan bagi Masyarakat berakhir.

HASIL DAN PEMBAHASAN

\section{A. Hasil Pengabdian Kepada Masyarakat}

Hasil yang telah dicapai dalam program pengabdian kepada masyarakat program pendidikan bagi Masyarakat dengan kegiatan Pelatihan dan Pendampingan Penulisan Artikel Ilmiah Hasil Penelitian Bermuatan Pendidikan Karakter Bagi Guru Mi Se-K3MI Kecamatan Kedungkandang1 Kota Malang, sampai dengan penyusunan laporan kemajuan sebagai berikut.

1) Kegiatan 1

Survey dan Diskusi Rencana Kegiatan. Kegiatan pengabdian ini dimulai dengan survey awal dan diskusi rencana kegiatan yang beragendakan penyusunan agenda kegiatan yang dilaksanakan selama program pelaksanaan pengabdian masyarakat. Diskusi rencana kegiatan dilaksanakan pada hari Sabtu, 13 April 2019. Kegiatan dilaksanakan selama satu hari yang bertempat di MI Nurul Hikmah. Pada diskusi rencana kegiatan ini melibatkan bebrapa guru untuk bertanya langsung tentang permasalahan yang muncul. Pada diskusi rencana kegiatan ini bertujuan untuk sharing dan mendapatkan masukan, umpan balik serta terjalin komunikasi yang baik dengan kelompok guru. Pada kegiatan ini juga disusun rencana kegiatan untuk pengabdian yang akan dlaksanakan selama dua hari dan telah disepakati oleh pihak sekolah. 


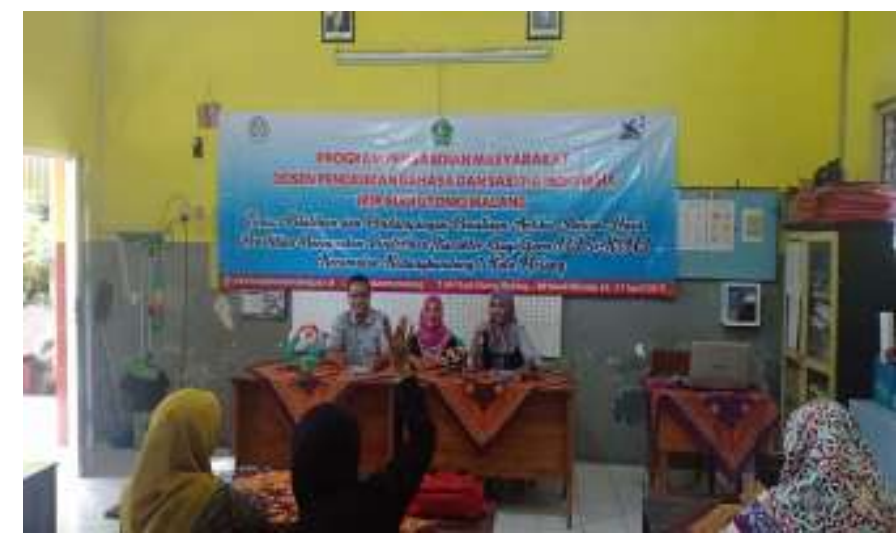

Gambar 1 Sosialisasi dan Diskusi Tentang Permasalahan yang Dihadapi

2) Kegiatan 2

Pemberian Materi Penulisan Artikel

Hari Pertama

Pemberian materi tentang penulisan artikel dilaksanakan pada hari pertama, yaitu tanggal
26 April 2019. Kegiatan hari pertama ini dibuka oleh ketua pengabdian dan dilanjutkan dengan pemberian materi oleh anggota 1 dan anggota 2 .

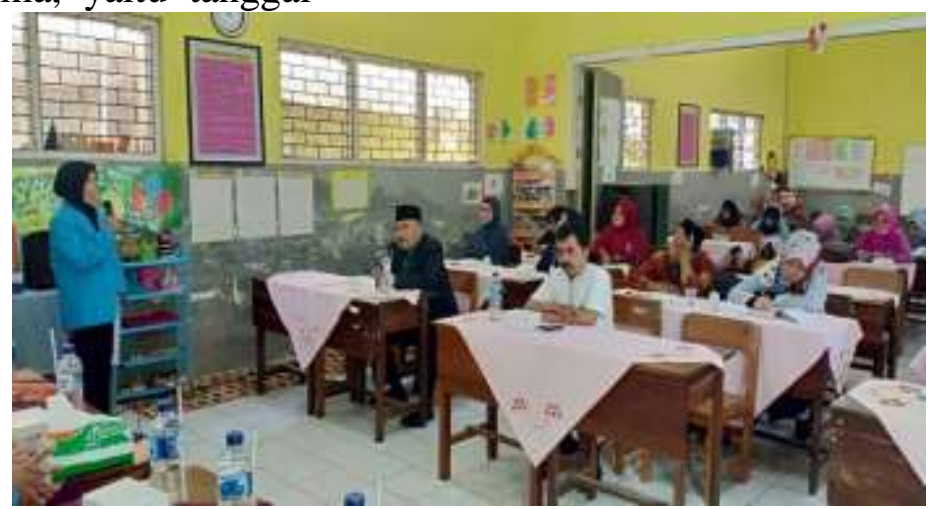

Gambar 2. Pembukaan oleh Ketua

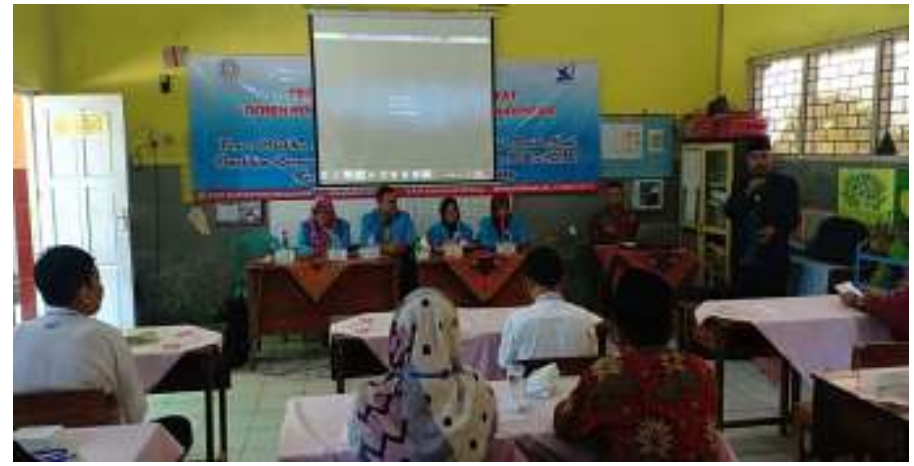

Gambar 3 Sambutan Ketua K3MI 


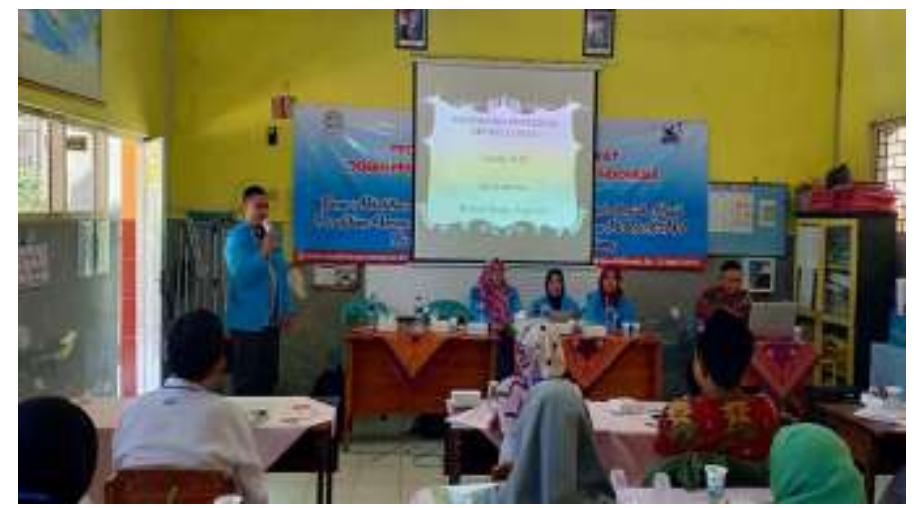

Gambar 4. Materi Pertama

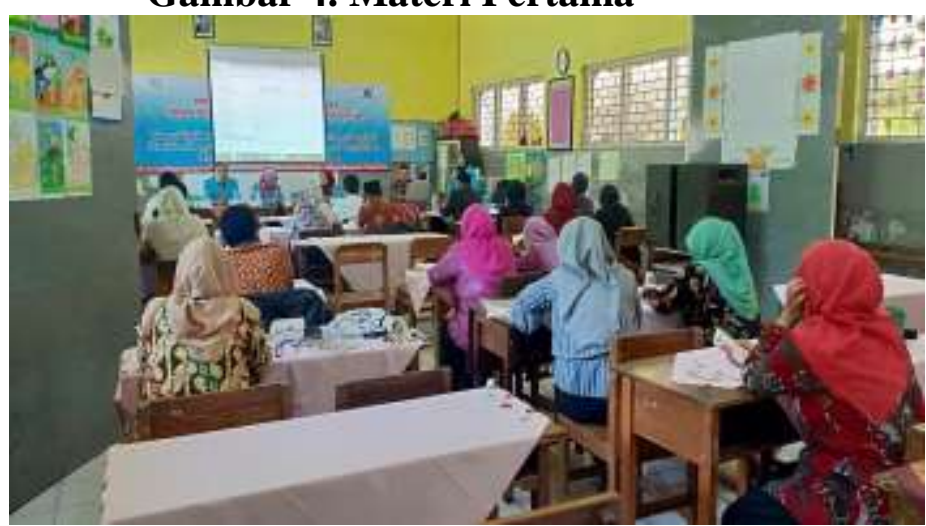

Gambar 5. Materi Kedua

3. Kegiatan 3

Pendampingan Penulisan Artikel

Kegiatan ini dilaksanakan untuk mengajak para guru untuk menerapkan materi yang telah diterima dan mengaplikasikannya ke dalam tulisan berbentuk artikel. Penulisan artikel yang sesuai dengan tema dan topik tulisan yang dihasilkan oleh guru.

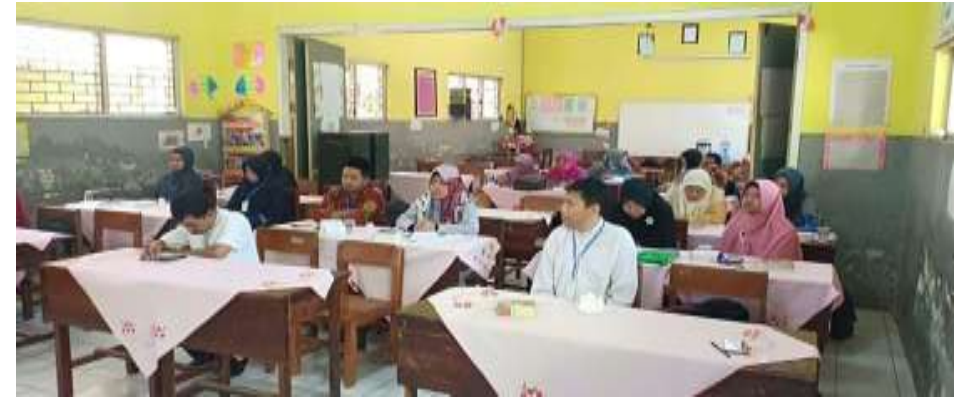

Gambar 6 Pendampingan Penulisan Artikel 


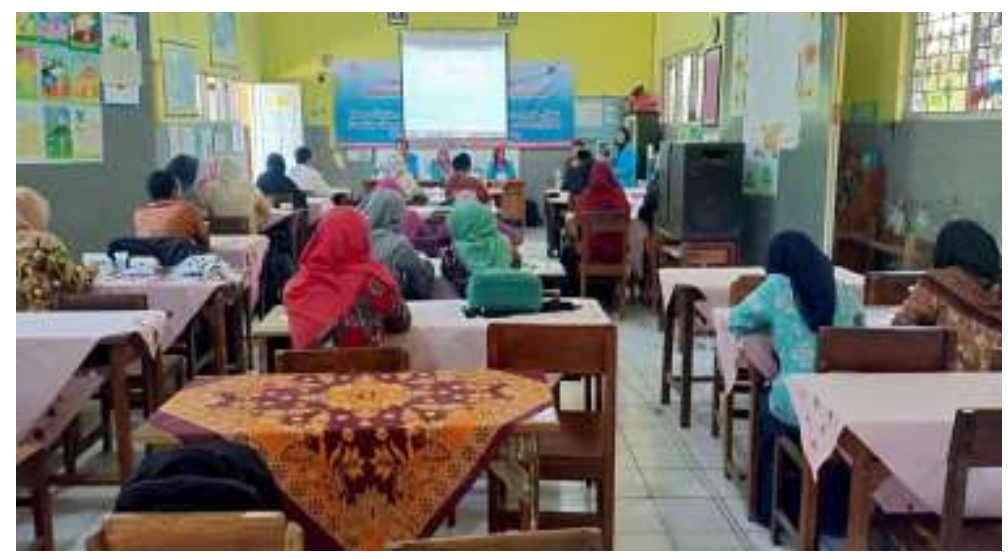

Gambar 7 Pendampingan Penulisan Artikel

\section{B. Pembahasan}

Peningkatan keterampilan pada peserta sesuai dengan teori experiental learning yang menyatakan bahwa metode pelatihan merupakan metode yang efektif meningkatkan pengetahuan dan keterampilan (Hariandja, 2012). Pelatihan merupakan sebuah proses mengajarkan pengetahuan dan keahlian tertentu serta sikap untuk semakin terampil dan mampu melaksanakan tanggung jawabnya dengan baik, sesuai dengan standar. (Mangkuprawira, 2004) mengatakan pelatihan merupakan metode yang efektif untuk mengubah struktur kognitif, memodifikasi sikap dan mengubah keterampilan karena melibatkan proses belajar yang efektif.

Peserta pelatihan yang semakin aktif dalam kegiatan pelatihan maka semakin banyak pengetahuan yang dimiliki karena semakin banyak informasi yang diperoleh dan peserta pelatihan dapat menerapkan secara langsung dalam kegiatan sehari-hari. Peningkatan keterampilan peserta setelah pelaksanaan pelatihan masih dalam tataran kognitif, dimana peserta baru saja memperoleh pengetahuan baru mengenai berbagai cara menyusun artikel. Idealnya, perkembangan skills dari pelatihan harus melewati tiga fase yaitu fase kognitif, fase asosiatif, dan fase autonomi (Randall, 2010).

Fase kognitif merupakan fase memperoleh pengetahuan intelektual mengenai ketrampilan yang dipelajari. Fase asosiatif adalah fase saat peserta kembali pada dunia kerja dan mencoba mempraktekkan perilaku baru sesuai dengan yang di pelajari selama pelatihan. Sedangkan fase autonomi adalah fase dimana perilaku telah muncul secara otomatis akibat proses pembiasaan. Pada penelitian ini, partisipan baru sampai pada fase kognitif, sehingga mereka belum merasakan manfaat secara langsung.

\section{KESIMPULAN}

Kegiatan

Masyarakat Program Pendidikan Masyarakat memiliki kesimpulan sebagai berikut. 1) Guru lebih baik menulis artikel sesuai dengan minat yang disenangi. Menulis sesuai dengan bidang yang dikuasai. Hal ini bertujuan untuk menghasilkan tulisan yang baik dan berkualitas. Bidang yang sesuai dapat dilakukan supaya hasil penulisan yang dihasilkan lebih baik. 2) Menyusun artikel bukan kegiatan yang tiba-tiba langsung jadi. Menulis artikel memerlukan waktu baik untuk artikel penelitian ataupun artikel konseptual. 
Sebelum menulis artikel akan lebih baik jika menulis kerangka terlebih dahulu agar hasilnya sistematis. 3) Menulis merupakan kegiatan yang memerlukan latihan berkali-kali. Tulisan yang baik dihasilkan dari penyusunan

paragraf yag kohesi dan koherensi sesuai dengan tema yang dipilih. Penulisan ini memerlukan latihan sehingga akan menghasilkan kualitas tulisan artikel yang baik. 4) Teori diperlukan untuk penguatan ide dan gagasan dalam menulis. Pemilihan teori pun harus disesuaikan dengan teori yang relevan dan tidak lebih dari lima tahun. Hal ini karena teori yang baru dirasa akan lebih relevan dengan permaslahan yang muncul di lapangan.

\section{DAFTAR RUJUKAN}

Hariandja. (2012). Manajemen Sumber Daya Manusia: Pengadaan, Pengembangan, Pengkompensasian dan Peningkatan Produktivitas Pegawai. Jakarta: Grasindo Widiasarana Indonesia.

Mangkuprawira, S. (2004). Manajemen Sumber Daya Manusia Strategik. Jakarta Selatan: Ghalia Indonesia.

Randal, R. \& Arnold, J. (2010). Work Psychology: $\quad$ Understanding Human Behavior in the Workplace. London: Pearson Education Limi 
